\title{
Synergistic estrogenic effects of Fusarium and Alternaria mycotoxins in vitro
}

\author{
Katharina Vejdovszky ${ }^{1}$ Kathrin Hahn ${ }^{1} \cdot$ Dominik Braun $^{1} \cdot$ Benedikt Warth $^{1} \cdot$ \\ Doris Marko ${ }^{1}$
}

Received: 25 February 2016 / Accepted: 5 July 2016 / Published online: 11 July 2016

(C) The Author(s) 2016. This article is published with open access at Springerlink.com

\begin{abstract}
Mycotoxins are toxic secondary metabolites formed by various fungal species that are found as natural contaminants in food. This very heterogeneous group of compounds triggers multiple toxic mechanisms, including endocrine disruptive potential. Current risk assessment of mycotoxins, as for most chemical substances, is based on the effects of single compounds. However, concern on a potential enhancement of risks by interactions of single substances in naturally occurring mixtures has greatly increased recently. In this study, the combinatory effects of three mycoestrogens were investigated in detail. This includes the endocrine disruptors zearalenone (ZEN) and $\alpha$-zearalenol ( $\alpha$-ZEL) produced by Fusarium fungi and alternariol $(\mathrm{AOH})$, a cytotoxic and estrogenic mycotoxin formed by Alternaria species. For evaluation of effects, estrogen-dependent activation of alkaline phosphatase (AlP) and cell proliferation were tested in the adenocarcinoma cell line Ishikawa. The estrogenic potential varied among the single substances. Half maximum effect concentrations (EC50) for AlP activation were evaluated for $\alpha$-ZEL, ZEN and AOH as $37 \mathrm{pM}, 562 \mathrm{pM}$ and $995 \mathrm{nM}$, respectively. All three mycotoxins were found to act as partial agonists. The majority of binary combinations, even at very low concentrations in the case of $\alpha$-ZEL, showed strong synergism in the AlP assay. These potentiating phenomena of mycotoxin mixtures highlight the urgent need to incorporate combinatory effects into future risk assessment, especially when endocrine disruptors are involved.
\end{abstract}

Doris Marko

doris.marko@univie.ac.at

1 Department of Food Chemistry and Toxicology, University of Vienna, Waehringer Str. 38, 1090 Vienna, Austria
To the best of our knowledge, this study presents the first investigation on synergistic effects of mycoestrogens.

Keywords Xenoestrogen · Natural toxin · Food safety · Food contaminants $\cdot$ Chemical mixtures

$\begin{array}{ll}\text { Abbreviations } \\ \text { AOH } & \text { Alternariol } \\ \text { ZEN } & \text { Zearalenone } \\ \alpha-Z E L & \alpha \text {-Zearalenol } \\ \text { E2 } & 17 \beta \text {-Estradiol } \\ \text { PBS } & \text { Phosphate-buffered saline } \\ \text { DMSO } & \text { Dimethyl sulfoxide } \\ \text { TCA } & \text { Trichloroacetic acid } \\ \text { SRB } & \text { Sulforhodamine B } \\ \text { CI } & \text { Combination index } \\ \text { SEM } & \text { Standard error of the mean } \\ \text { AlP } & \text { Alkaline phosphatase } \\ \text { LOEL } & \text { Lowest observed effect level } \\ \text { NOEL } & \text { No observed effect level }\end{array}$

\section{Introduction}

Mycotoxins are toxic compounds produced as secondary metabolites by molds. Contamination of food crops may occur on the field or post-harvest. This leads to the entrance of mycotoxins into the food chain and consequently to a potential risk for human health (Bennett and Klich 2003). The variety of fungal species capable of producing mycotoxins is vast, leading to an even larger diversity of over 300 secondary fungal metabolites already known to possess toxic properties. Studies on mycotoxin contamination profiles in feed and foodstuff reveal that compounds generally do not occur isolated, but in complex mixtures 
(Domijan et al. 2005; Ezekiel et al. 2012; Serrano et al. 2013; Shephard et al. 2013; Streit et al. 2013). In addition, these co-contaminations are not limited to mycotoxins produced by one certain fungal genus. Accordingly, co-occurrence of mycotoxins of different genera, like Fusarium toxins and Alternaria toxins, is evident (Sulyok et al. 2010; Uhlig et al. 2013; Warth et al. 2012). As the variety of naturally occurring compounds may suggest, specific modes of action of mycotoxins and manifestation of their toxic effects in humans and animals are highly diverse. Among many other mechanisms of toxicity, several mycotoxins are known for their mutagenicity and genotoxicity, while others may act on cell membrane permeability, inhibit protein synthesis, or induce inflammatory responses (Gross-Steinmeyer and Eaton 2012; Kamyar et al. 2004; Pestka 2010). Interestingly, some mycotoxins also possess endocrine disruptive potential. The most prominent mycoestrogen is the Fusarium toxin zearalenone (ZEN) which is capable of binding and activating both human estrogen receptors, $\alpha$ and $\beta$ (ER- $\alpha$, ER- $\beta$ ) due to its structural similarity to the body's own natural hormone $17-\beta$-estradiol (E2). It is described as a full agonist for ER- $\alpha$ and a mixed agonist-antagonist for ER- $\beta$ (Kuiper et al. 1998). After absorption, ZEN is partly hydroxylated to $\alpha$ - and $\beta$-zearalenol ( $\alpha$-ZEL, $\beta$-ZEL), which are subsequently reduced to $\alpha$ - and $\beta$-zearalanol ( $\alpha$-ZAL, $\beta$-ZAL) and/or conjugated with glucuronic acid during phase II metabolism (Frizzell et al. 2015; Warth et al. 2013). Studies on the estrogenic activity of ZEN, and its metabolites, revealed that $\alpha$-ZEL possesses even stronger estrogenic properties than ZEN itself, whereas $\beta$-ZEL is less active (Frizzell et al. 2011; Hagler et al. 1979; Metzler et al. 2010). Due to these effects, ZEN induces estrogenic conditions, especially in swine, which initially resulted in the discovery of this toxin (Coe et al. 1992; McErlean 1952; Stob et al. 1962). Several studies postulate endocrine disruptive potential also in humans. ZEN is known to mediate proliferative effects on estrogen-dependent cancer cells of the breast or the endometrium ( $\mathrm{Li}$ et al. 2012a). Recent epidemiological studies associate ZEN with perturbed breast development and increased breast cancer risk; however, these studies concentrated on the evaluation of biomarkers in urine which only reflects short-term exposure (Bandera et al. 2011; Belhassen et al. 2015). Apart from its estrogenic activity, ZEN also holds DNA damaging properties and induces oxidative stress (Abid-Essefi et al. 2004; Gao et al. 2013). These effects are supposedly causally connected to cytotoxic effects and are diminished by hydroxylation to $\alpha$-ZEL or $\beta$-ZEL (Abid-Essefi et al. 2004, 2009). Alternariol (AOH), produced by fungi of the genus Alternaria, is another mycotoxin capable of inducing estrogenic stimuli. However, this effect of $\mathrm{AOH}$ is predominantly mediated via ER- $\beta$, which is bound with approximately ten-fold higher affinity than ER- $\alpha$ (Frizzell et al. 2013; Lehmann et al. 2006). Similar to ZEN, AOH possesses cytotoxic potential and has been found to induce oxidative stress and DNA damage (Fehr et al. 2009; Tiessen et al. 2013). In vitro estrogenicity and cytotoxicity are, in some measure, quite contrary as estrogenic effects often involve growth stimuli. Supposable criteria to be decisive for the dominant impact are primarily the amount of mycotoxin, but also the duration of exposure. In vivo, predominant effects may additionally be influenced by specificities of target organ tissues concerning available estrogen receptors and metabolizing enzymes.

Recently developed innovative LC-MS/MS-based multi-toxin methods revealed the common occurrence of Fusarium and Alternaria toxins in food and feed (Sulyok et al. 2010; Uhlig et al. 2013; Warth et al. 2012). Therefore, the importance to evaluate combinatory effects of compounds produced by these genera is evident, as humans and animals are constantly exposed to co-contaminated diets. Any kind of effect inherent to a mycotoxin, like cytotoxicity, genotoxicity or estrogenicity, may potentially be influenced by interactions with other mycotoxins. Currently, insufficient research effort is put into the elucidation of mixture-effects involving endocrine disruptive mycotoxins despite its great importance regarding consumer's risk.

The experimental design of this study aims to give a detailed profile on the combinatory estrogenic effects of the mycotoxin ZEN, its most potent estrogenic metabolite $\alpha$-ZEL, as well as $\mathrm{AOH}$. Wide concentration ranges were tested, in order to cover realistic in vivo exposure scenarios of low levels in the body, as well as rare conditions of high exposure. Massart et al. (2008) reported mean serum levels of ZEN and $\alpha$-ZEL in girls with precocious puberty of about $3 \mathrm{nM}$ and $300 \mathrm{pM}$, respectively. Unfortunately, specific serum levels of $\mathrm{AOH}$ have not been investigated so far. However, mean $\mathrm{AOH}$ concentrations of about $50 \mathrm{nM}$ were found in bakery products, but also much higher levels of about $97 \mathrm{nM}$ in tomato products, $151 \mathrm{nM}$ in sunflower seeds and $380 \mathrm{nM}$ in wheat flour were detected (Hickert et al. 2016; Zhao et al. 2015). Here, several magnitudes below and above these serum levels or concentrations found in foodstuff were tested. Well-established tests on estrogenic stimuli and proliferation were conducted under equal testing conditions, for the detection of transcriptional response and cell growth induction, but also to monitor possible cytotoxic effects. Our study presents first insights into combinatory estrogenic effects of mycotoxins.

\section{Materials and methods}

\section{Chemicals and reagents}

Cell culture media and supplements were purchased from GIBCO Invitrogen (Karlsruhe, Germany). Alternariol, 
a<smiles>Cc1ccc2c(c1)CCC1C2CCC2(C)C1CC[C@H]2O</smiles>

$17-\beta$ estradiol (E2)<smiles>Cc1cc(O)cc2oc(=O)c3c(O)cc(O)cc3c12</smiles>

alternariol $(\mathrm{AOH})$<smiles>Cc1cc(O)c(C(=O)OC(C)CCCC(=O)CCC/C=C/c2cc(O)cc(O)c2)c(O)c1</smiles>

zearalenone

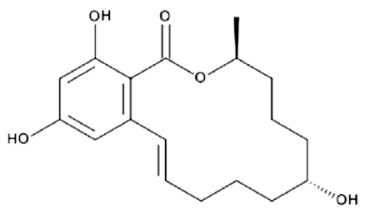

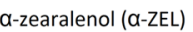

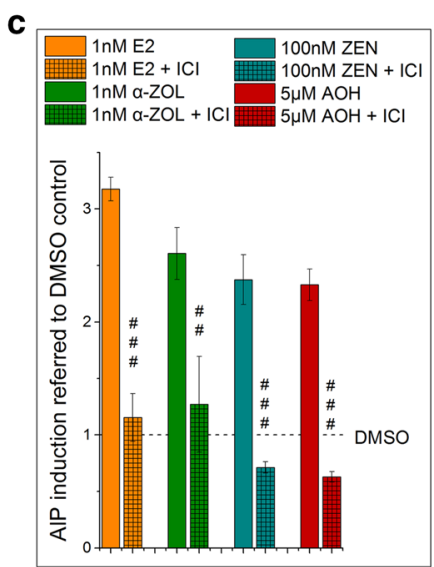

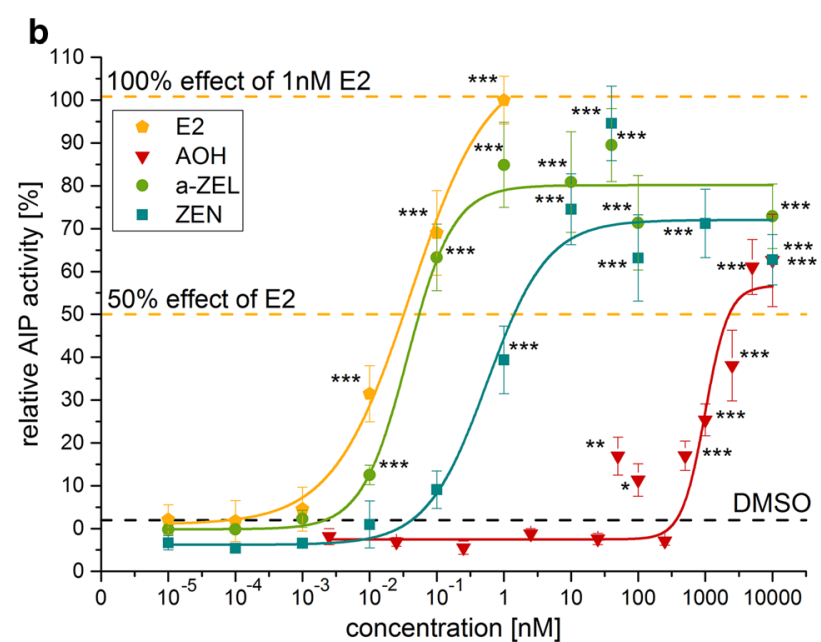

Fig. 1 E2 and selected mycotoxins: estrogenic activity in the alkaline phosphatase (AIP) assay and impact on the growth of Ishikawa cells. a Chemical structures. b Dose-response curves in the AlP assay (mean, SEM). c Inhibition of estrogenic effects in the AIP assay by co-incubation with the ER receptor antagonist ICI 182,780 (mean, SEM). d Impact on cellular protein amount determined by

zearalenone, $\alpha$-zearalenol, $17-\beta$-estradiol, 4 -nitrophenylphosphate, diethanolamine and $\mathrm{MgCl}_{2}$ were purchased from Sigma-Aldrich (Schnelldorf, Germany). DMSO, Triton X-100 and Tris were purchased from Roth (Karlsruhe, Germany). Trichloroacetic acid was purchased from VWR (Radnor, PA, USA). ICI 182,780 was purchased from Tocris (Bristol, United Kingdom). Chemical structures of the tested substances are shown in Fig. 1a.

\section{Experimental design}

The aim of this in vitro study was to investigate estrogenic effects of combinations of AOH with ZEN or its metabolite $\alpha$-ZEL. The estrogen-sensitive human endometrial adenocarcinoma cell line, Ishikawa, is a well-suited model system for the detection of estrogenic stimuli (Holinka et al. 1986; Johnson et al. 2007; Lehmann et al. 2006) and was

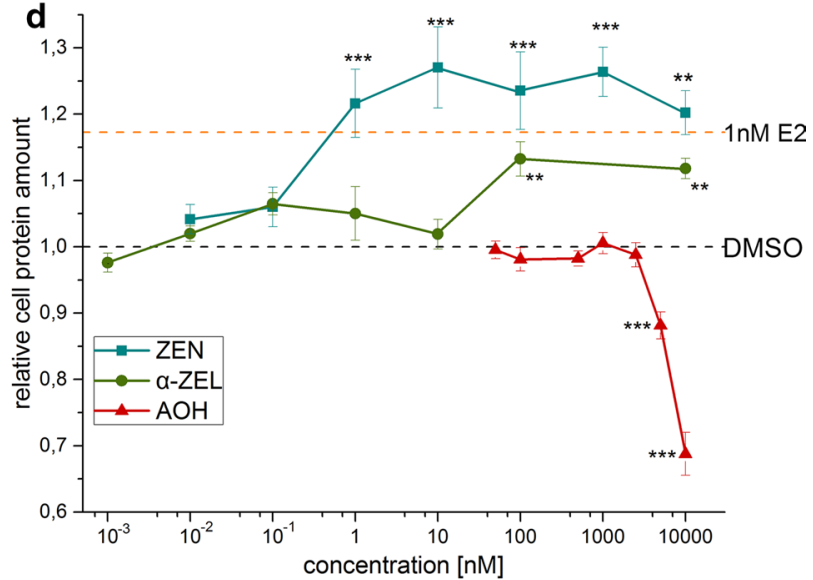

the SRB assay (mean, SEM). Significant differences to the solvent control (DMSO), or significant differences of co-incubations with ICI 182,780 to single tested substances are indicated by asterisks. All measurements were repeated in at least three independent biological replicates, each measured in technical triplicates. $\left({ }^{*} p>0.05\right.$; $* * p>0.01 ; * * p>0.001)$

chosen as model system for this study. Two assays were used to evaluate estrogenic properties. Transcriptional response to estrogens was evaluated by assessment of alkaline phosphatase activity, encoded by a gene, which is transcriptionally activated upon estrogen receptor activation. The sulforhodamine B assay (SRB) assay was performed to investigate a potential impact on cell growth and at high concentrations of mycotoxins, accordingly, cytotoxic effects. Incubation conditions of both assays were kept equal, to enable a direct comparison of the obtained results.

Preliminary measurements of concentration ranges of the natural estrogen hormone E2 as well as AOH, ZEN and $\alpha$-ZEL were taken in the AlP assay. Due to the low solubility of $\mathrm{AOH}$, a final concentration of $1 \%$ DMSO in the incubation solution needed to be applied. For details on measured concentrations, see Fig. 1b. The most potent concentration of $\mathrm{E} 2,1 \mathrm{nM}$, was always tested in parallel and served as positive 
control for estrogenic stimuli. Measurements of $1 \%$ of the solvent, dimethyl sulfoxide (DMSO), were taken as solvent control. To confirm that effects arise from estrogenic stimuli, E2 and most potent concentrations of single substances and combinations were co-incubated with $1 \mu \mathrm{M}$ of the highaffinity estrogen receptor antagonist ICI 182,780. Inhibition of effects by adding ICI 182,780 indicates the involvement of estrogen receptors. Sigmoidal dose-response curve fitting with Levenberg-Marquardt algorithm was applied on data of each single substance. EC50 values and concentrations of single substances reaching the half maximum effect of E2 were extracted from the dose-response curves.

In order to ensure comparability of the data, measurements of combinations were always taken in parallel to measurements of respective single substances at exactly the same concentrations. To ensure a detailed elucidation of combinatory effects between ZEN and AOH or $\alpha$-ZEL and $\mathrm{AOH}$, all concentrations which showed effects as single substances (ZEN $10 \mathrm{pM}-10 \mu \mathrm{M} ; \alpha$-ZEL $1 \mathrm{pM}-10 \mu \mathrm{M}$; AOH $50 \mathrm{nM}-10 \mu \mathrm{M}$ ) were combined with each other in binary mixtures. In addition, combinations in constant concentration ratios were measured in order to elucidate whether dose-response curves of ZEN and $\alpha$-ZEL are shifted when combined with $\mathrm{AOH}$. Based on the preliminary measurements, the ratio of 1:250 (ZEN/ $\alpha-Z E L / A O H)$, which gave highly potent effects in both combinations, was chosen for these evaluations. Here, measured concentrations ranged for ZEN and $\alpha$-ZEL from $10 \mathrm{fM}$ to $40 \mathrm{nM}$ and for $\mathrm{AOH}$ from $2.5 \mathrm{pM}$ to $10 \mu \mathrm{M}$.

\section{Cell culture}

The human endometrial adenocarcinoma cell line Ishikawa was purchased from ECACC (Wiltshire, United Kingdom). Cells were cultivated in humidified incubators $\left(37^{\circ} \mathrm{C}\right.$, $5 \% \mathrm{CO}_{2}$ ) in phenol red free Dulbecco's Modified Eagle's Medium containing F-12 Nutrient Mixture (DMEM/F-12) and $10 \%$ FBS (Fetal Bovine Serum). For experiments, FBS was exchanged by charcoal-dextran stripped FBS, which provides low levels of hormones. For all assays, $24 \mathrm{~h}$ previous to incubation, Ishikawa cells were seeded at a density of 15,000 cells per well into a 96 well plate. Incubation of AOH, ZEN, $\alpha$-ZEL and all tested combinations was conducted for $48 \mathrm{~h}$, at a final solvent concentration of $1 \%$ DMSO. Details on tested concentrations are indicated in all figures. All measurements were taken at minimum in three independent biological replicates, each measured in technical triplicates.

\section{Alkaline phosphatase assay}

This assay was conducted as previously described (Lehmann et al. 2006) and optimized. After 48 h of incubation, cells were washed three times with PBS, before cell lysis was initiated by keeping the cells at $-80{ }^{\circ} \mathrm{C}$ for $20 \mathrm{~min}$. Subsequently, the cell lysate was kept at room temperature for $5 \mathrm{~min}$. $50 \mu \mathrm{l}$ AlP buffer $(5 \mathrm{mM}$ 4-nitrophenylphosphate, $1 \mathrm{M}$ diethanolamine, $0.24 \mathrm{mM} \mathrm{MgCl} 2, \mathrm{pH}$ 9.8) was added to each well and was incubated for $5 \mathrm{~min}$. Measurements of absorbance were taken at $405 \mathrm{~nm}$, every $2 \mathrm{~min}$, for $1 \mathrm{~h}$, at $37^{\circ} \mathrm{C}$, with the Cytation 3 Cell Imaging Multi-Mode Reader from Biotek ${ }^{\circledR}$ (Winooski, Vermont, USA). The activity of the alkaline phosphatase was calculated as the slope of the curve, obtained by the measurements monitored over $1 \mathrm{~h}$. Final results were referred to the solvent control.

\section{SRB assay}

This assay was conducted according to Skehan et al. (1990). After $48 \mathrm{~h}$ of incubation, $10 \mu \mathrm{l}$ of $50 \%$ TCA (trichloroacetic acid) was added to each well and incubated for $1 \mathrm{~h}$, at $4{ }^{\circ} \mathrm{C}$, in the dark, to facilitate the fixation of cells. Subsequently, cells were washed four times with $\mathrm{H}_{2} \mathrm{O}$. The plate was dried at room temperature in the dark, prior to the addition of $50 \mu$ of SRB reagent $(0.4 \%$ mass concentration SRB in $1 \%$ acetic acid solution) per well, and further incubation for $1 \mathrm{~h}$ at room temperature in the dark. Afterward, wells were washed twice with $\mathrm{H}_{2} \mathrm{O}$ and twice with $1 \%$ acetic acid solution, before the plate was dried at room temperature in the dark. Finally, $100 \mu \mathrm{l}, 10 \mathrm{mM}$ Tris solution (pH 10) was added, incubated for $5 \mathrm{~min}$, in the dark, and absorbance was measured at $570 \mathrm{~nm}$, using the Victor V3 1240 Multilable Counter from Perkin Elmer (Waltham, Massachusetts, USA). Final results were referred to the solvent control.

\section{Evaluation of combinatory effects in an estrogenic system}

Combinatory effects were determined as described previously by Vejdovszky et al. (2016) with minor adaptions to measurements of estrogenic stimuli.

\section{Combination index theorem}

For CI evaluation, effects were calculated by the following formula, where max is the chosen maximum value of 3.7, $y_{\mathrm{C}}$ is the measurement of the DMSO solvent control, to which all data are referred to, and $x_{\mathrm{T}}$ is the measured value of the tested substance or combination.

effect $=\frac{1}{\max } *\left(\frac{x_{\mathrm{T}}}{y_{\mathrm{C}}}\right)$

According to Chou et al. (1975, 1984), measured effects of combinations were evaluated for synergism, antagonism or additivity, based on the medium effect equation and the combination index theorem (Chou 1975; Chou and Talalay 1984). 
The equation below specifies the calculation of the combination index (CI). $D_{1}$ and $D_{2}$ represent applied mycotoxin concentrations in the combination. $D \mathrm{~m}$ and $m$ are two parameters determined via the medium effect equation and describe the potency and the shape of the dose-response curves of each mycotoxin. The actual effect of the combination is termed $f a$.

$C I=\frac{D_{1}}{D \mathrm{~m}_{1}[f a / 1-f a]^{1 / m 1}}+\frac{D_{2}}{D \mathrm{~m}_{2}[f a / 1-f a]^{1 / m 2}}$

A combination index (CI) value of one indicates additive effects, whereas a $\mathrm{CI}<1$ indicates synergism, and CI $>1$ antagonism. A detailed classification of CI values was applied according to Chou (2006) and is illustrated in Fig. 3. As suggested by Chou (2006), the most exact evaluation of combinatory effects is achieved by measuring combinations in constant ratios, which allows comparing dose-response relations of the combination with the single substances based on the medium effect equation. CI values can thereby be calculated for the whole effect range of the combination and graphically displayed in the effect-CI plot.

\section{Statistics}

All measurements of combinations, in the AlP assay and the SRB assay, were taken in at least three biological replicates, each in technical triplicates. The whole dose range of respective single substance was always measured in parallel. Significance levels were set to $5 \%\left({ }^{\#}, * p>0.05\right.$; \#\#, **p >0.01; \#\#, $* * * p>0.001)$. All data were tested for normality by Kolmogorov-Smirnov test. Significant differences of all measurements, compared to the solvent control, or to the respective ZEN or $\alpha$-ZEL concentration effect, were evaluated via one-way ANOVA and Bonferroni post hoc test. For statistical comparison of all measurements to $1 \mathrm{nM} \mathrm{E} 2$ with and without ICI 182,780, Student's $t$ test was applied. Statistical analyses were performed with OriginPro 9.1 G (Origin Lab, Massachusetts).

\section{Results}

\section{Estrogenic stimuli: activation of alkaline phosphatase}

Estrogenic effects of single mycotoxins on Ishikawa cells (human endometrial adenocarcinoma) were evaluated after $48 \mathrm{~h}$ of exposure, by measuring AlP activity. Sigmoidal dose-response curve fitting was performed for each single substance. By this analysis, the effective concentration that induces $50 \%$ response (EC50), a commonly used measure of toxin potency, can be determined. EC50 values for E2, $\alpha$-ZEL, ZEN and AOH were calculated as 41,37, $562 \mathrm{pM}$ and $995 \mathrm{nM}$, respectively (Fig. 1b). However, these EC50 values
Table 1 EC50 values and concentrations of single substances reaching $50 \%$ of the effect of E2

\begin{tabular}{lll}
\hline & EC50 & $50 \%$ effect of E2 $^{\mathrm{b}}$ \\
\hline AOH & $995 \mathrm{nM}$ & $2.251 \mathrm{nM}$ \\
$\alpha-Z E L$ & $37 \mathrm{pM}$ & $55 \mathrm{pM}$ \\
ZEN & $562 \mathrm{pM}$ & $1.423 \mathrm{nM}$ \\
\hline
\end{tabular}

${ }^{\text {a }}$ Concentration that gives $50 \%$ of the maximum effect level of each single substance

b Concentration that gives $50 \%$ of the effect of $1 \mathrm{nM} \mathrm{E2}$

are related to the respective maximum effect level of each single substance which indeed vary, as it is apparent in Fig. 1b. A direct comparison of EC50 values may therefore not be very meaningful. To enable a more reasonable comparison of the curves, concentrations of each single substance which reach $50 \%$ of the effect of E2 were extracted from the doseresponse curves. Table 1 lists these concentrations in comparison with the EC50 values. To confirm that the observed effects indeed arose from estrogenic stimuli, most potent concentrations of all substances were co-incubated with the high-affinity estrogen receptor antagonist ICI 182,780. Corresponding results, shown in Fig. 1c, demonstrated that the effects of all substances can be suppressed by ICI 182,780 and are therefore considered to depend on estrogen receptor activation.

The maximum induction of AlP activity, measured in this experimental setup, was not reached by any single substance, not even by the human hormone E2. At its most potent concentration of $1 \mathrm{nM}$, E2 reached a mean induction of 3.2-fold compared to the solvent control. This value was defined as $100 \%$. The maximum induction of AlP activity in this system was measured in combination tests of $10 \mathrm{nM}$ ZEN and $5 \mu \mathrm{M} \mathrm{AOH}$, which was on average 3.4-fold higher compared to the solvent control. Several other combinations of ZEN and AOH, but also of $\alpha$-ZEL and $\mathrm{AOH}$, showed effects which also exceeded the effect of $1 \mathrm{nM}$ E2 (see Fig. 2i-iv) . However, these findings were not statistically significant to measurements of $1 \mathrm{nM}$ E2 $(p<0.05)$. All measured effects of single substances and combinations are reported in the heatmaps A (ZEN) and B $(\alpha-Z E L)$ in Fig. 2. Results are expressed as percentage of induction, where 0 and $100 \%$ represent the values of the solvent control and of $1 \mathrm{nM}$ E2, respectively. Significant AlP activation, compared to solvent control, is indicated by asterisks. The color code of these heatmaps indicates the strength of the effect, which enables a visual interpretation of results of all tested combinations. $\mathrm{AOH}$ was found to increase the estrogenic effects of both Fusarium toxins in almost all tested concentrations. Only AOH in concentrations below $2.5 \mu \mathrm{M}$ in combination with ZEN below $10 \mathrm{nM}$ did not increase AlP activity significantly. Some combinations of $\alpha$-ZEL below $100 \mathrm{pM}$ and AOH below $1 \mu \mathrm{M}$ 

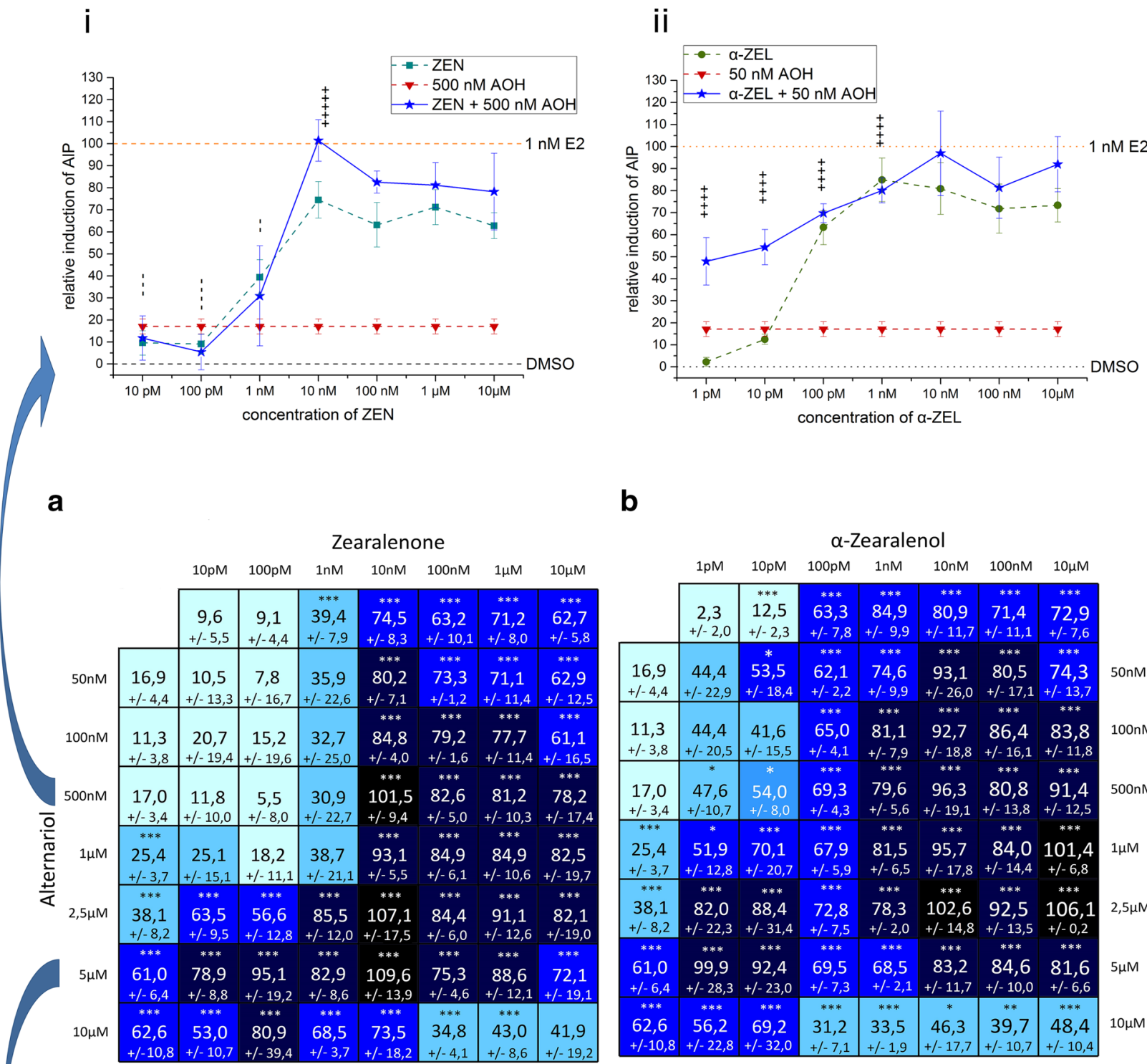

b

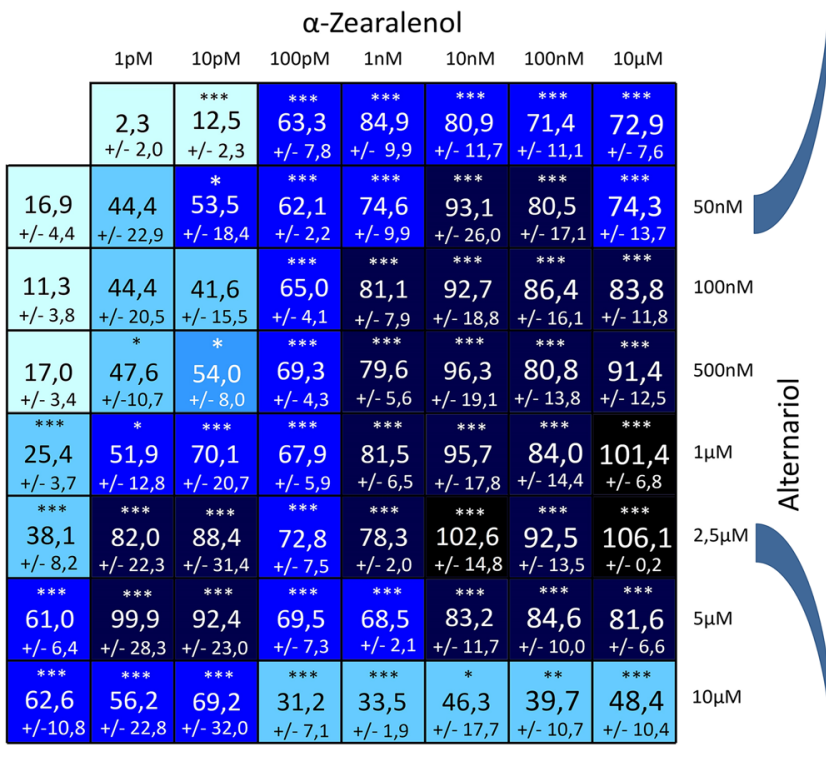

The colour code indicates AIP activity referred to the effect of $1 \mathrm{nM}$ E2 [\%].
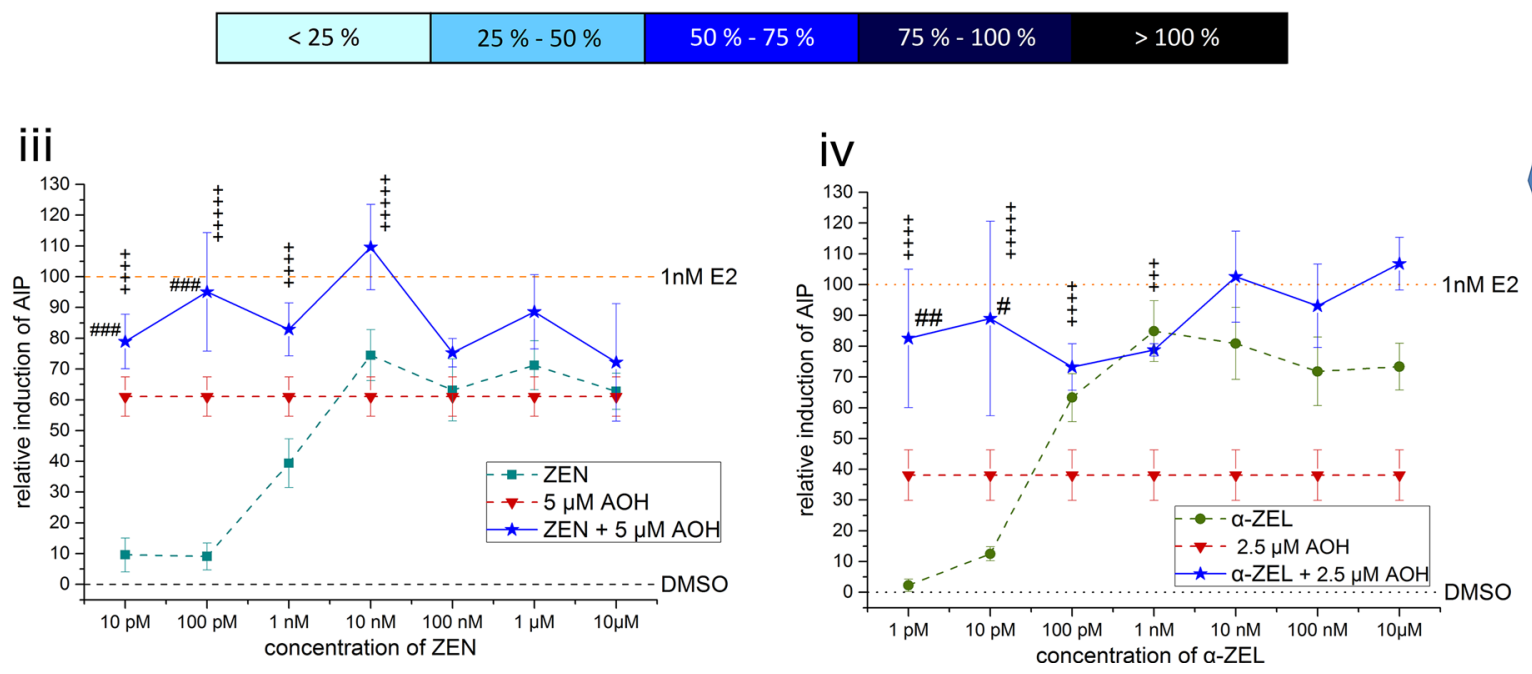
4 Fig. 2 Heatmaps showing relative effects on AlP activity of Ishikawa cells by single mycotoxins and binary combinations of $\mathrm{AOH}$ with a ZEN or $\mathbf{b} \alpha$-ZEL (mean, SEM). Effects of solvent control and $1 \mathrm{nM}$ E2 were set to 0 and $100 \%$, respectively. Four line graphs covering whole concentration ranges of ZEN or $\alpha$-ZEL in combination with one low (i, ii) and one high (iii, iv) concentration of $\mathrm{AOH}$ are extracted exemplary from the data set for comparison with the effects of single substances. Significant differences of effects to the solvent control are indicated by asterisks, significant differences of the binary mixtures to measurements with ZEN or $\alpha$-ZEL, as single compounds, are indicated by hash marks $\left(*,{ }^{\#} p>0.05\right.$; **, ${ }^{\# \#} p>0.01$; ***, $\# \#$ > 0.001). CI values are indicated by + or - , and reflect categorization of interactions according to Chou (2006). All measurements were repeated in at least three independent biological replicates, each measured in technical triplicates

were found to show significant induction of AlP activity. Both data sets, the combinations of AOH with either ZEN or $\alpha$-ZEL, showed similar trends. Effects were most pronounced at somewhat medium concentrations, but decrease at very high doses. Concentrations of $0.5-2.5 \mu \mathrm{M}$ of $\mathrm{AOH}$ were found to mediate the most potent effects on the estrogenic activity of ZEN and $\alpha$-ZEL.
In order to visualize the impact of $\mathrm{AOH}$ on the estrogenic effects of ZEN and $\alpha$-ZEL, four exemplary graphs were drawn out of the data set. For each Fusarium compound, two line graphs are plotted, showing effects of combinations with $\mathrm{AOH}$, in one low (Fig. 2i, ii) and one high concentration (Fig. 2iii, iv), in comparison with the effects of the single substances.

Combinatory effects of $\mathrm{AOH}$ and low concentrations of ZEN or $\alpha$-ZEL (ZEN: concentrations below $100 \mathrm{nM}$; $\alpha$-ZEL: concentrations below $10 \mathrm{nM}$ ) were calculated via the combinatory index $(\mathrm{CI})$ and categorized according to Chou (2006), regarding synergism or antagonism. To enable correct CI calculations, the maximum value for AlP activity was set slightly above the maximum measured value (3.4 fold induction) compared to the solvent control. Due to the special characteristics of dose-response curves of all three mycotoxins (discussed below), CI calculations of combinations of high concentrations were not applicable. Figure 3 illustrates combinatory effects with CI values indicated by the color code. Significant differences
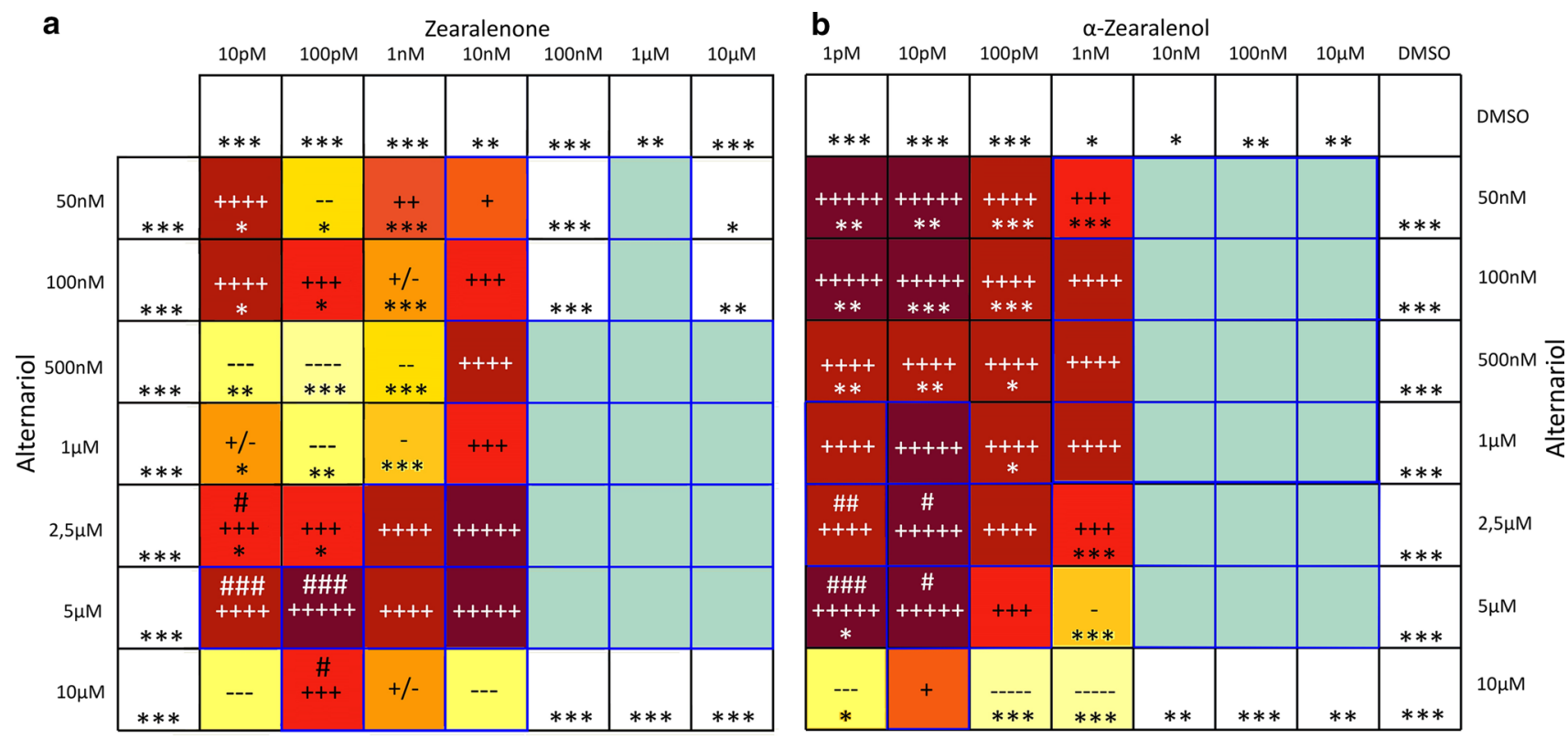

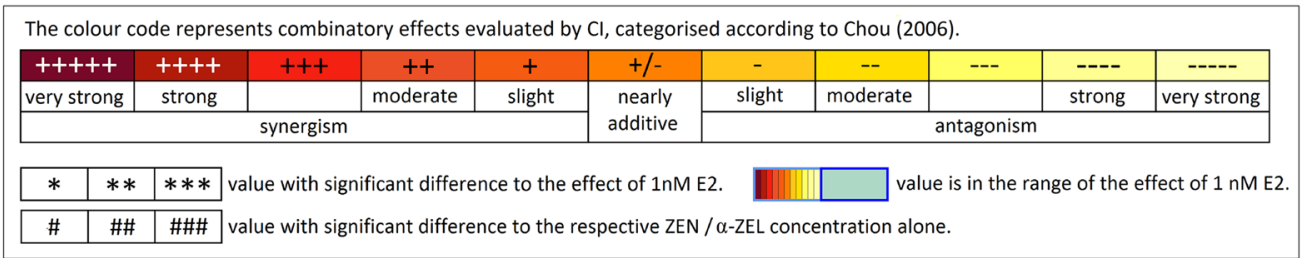

Fig. 3 Heatmaps depicting combinatory effects of binary mixtures of AOH with a ZEN or $\mathbf{b} \alpha$-ZEL calculated on basis of AlP activity. The color code represents combinatory effects evaluated by the CI and are categorized according to Chou (2006). Significant differences of effects to the solvent control are indicated by asterisks, significant differences of the binary mixtures to measurements with
ZEN or $\alpha$-ZEL, as single compounds, are indicated by hash marks $\left(*,{ }^{\#} p>0.05\right.$; **, $\left.{ }^{\# \#} p>0.01 ; * * *,{ }^{\# \#} p>0.001\right)$. Combinations with nonsignificant differences to the effect of $1 \mathrm{nM}$ E2 are highlighted in gray and/or framed in blue. All measurements were repeated in at least three independent biological replicates, each measured in technical triplicates (colour figure online) 
between values of combinations to the respective ZEN or $\alpha$-ZEL concentration tested alone are indicated by hash marks. In addition, Fig. 3 shows significant differences of single substances and binary combinations, compared to the effect of $1 \mathrm{nM}$ E2, indicated by asterisks. Some combinations showed higher effects than E2, while all tested concentrations of single substances exhibited significant lower effects.

Low concentrations of ZEN (up to $1 \mathrm{nM}$ ) in combinations with $\mathrm{AOH}$, at concentrations below $2.5 \mu \mathrm{M}$, exhibited some antagonistic effects. However, most combinations from 1 nM ZEN with AOH were found to have synergistic effects. Synergism was also mediated by the majority of higher concentrated mixtures of $\mathrm{AOH}$ and ZEN. A very broad concentration range of $\alpha$-ZEL ( $1 \mathrm{pM}-1 \mathrm{nM})$ was found to have highly synergistic effects in combination with $\mathrm{AOH}$ (see Fig. 3). In both data sets, the majority of combinations tested, especially in high doses, were not found to be significantly different to the effect of $1 \mathrm{nM} \mathrm{E} 2$, thus mediating substantial estrogenic effects in the range

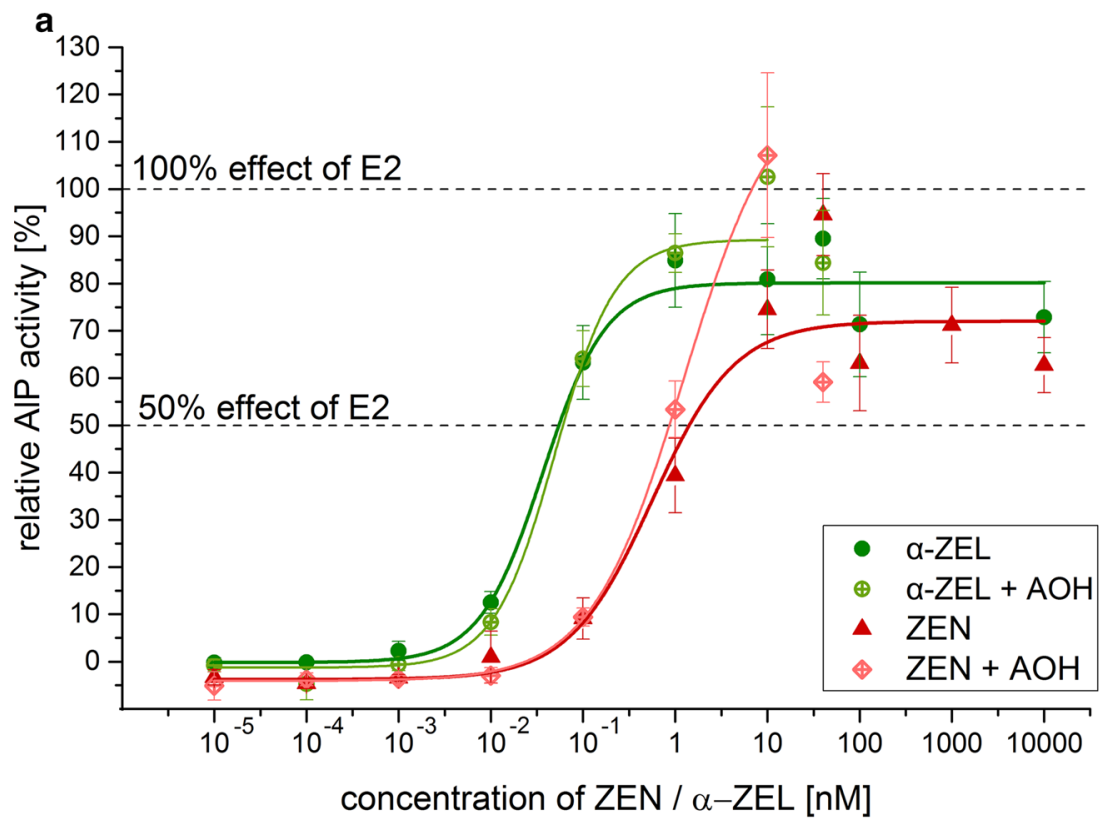

b
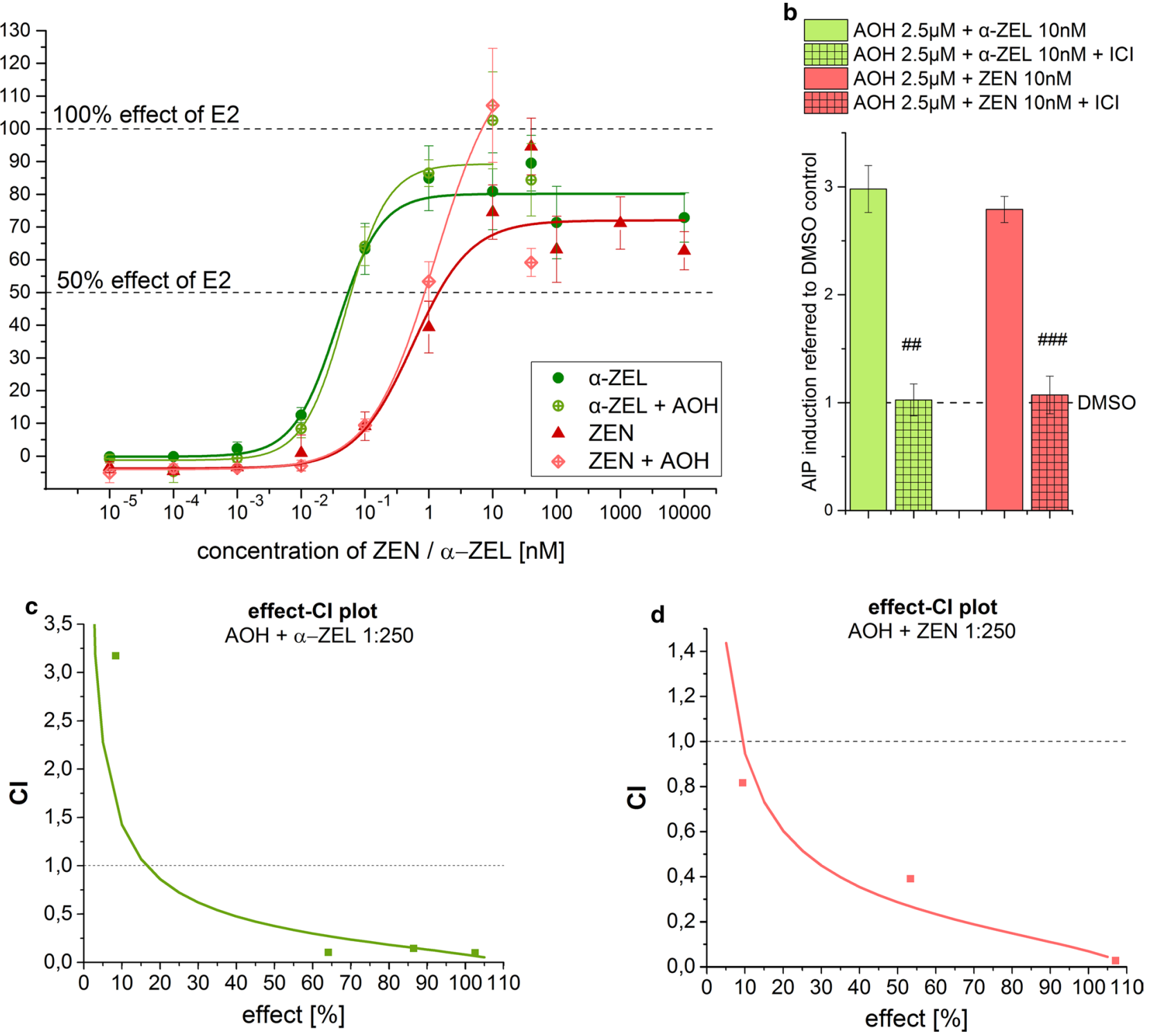

Fig. 4 Measurements of combinations in constant ratios of 1:250 (ZEN or $\alpha$-ZEL:AOH) in the AlP assay. a Sigmoidal dose-response curve fits of combinations $\mathrm{ZEN}+\mathrm{AOH}$ and $\alpha-\mathrm{ZEL}+\mathrm{AOH}$ in comparison to dose-response curves of ZEN and $\alpha$-ZEL alone (mean, SEM). b Inhibition of estrogenic effects of highly potent combinations ( $10 \mathrm{nM}$ ZEN or $10 \mathrm{nM} \alpha-\mathrm{ZEL}+2.5 \mu \mathrm{M} \mathrm{AOH})$ in the AlP assay by co-incubation with the ER receptor antagonist ICI 182,780 (mean,

SEM). Combinatory index (CI) evaluation of constant ratio combinations 1:250 of $\mathbf{c} \alpha-\mathrm{ZEL}+\mathrm{AOH}$ or $\mathbf{d} \mathrm{ZEN}+\mathrm{AOH}$ are represented in effect-CI plots $(\mathrm{CI}<1$ indicates synergism; $\mathrm{CI}=\sim 1$ indicates additive effects; CI $>1$ indicates antagonism): Dots display CI values of measured combinations (a), lines display calculated CI values based on medium effect equation (MEE) analysis of the dose-response curve of combinations 
Table 2 EC50 values and concentrations of constant ratio combinations reaching $50 \%$ of the effect of E2

\begin{tabular}{|c|c|c|c|c|}
\hline & \multicolumn{2}{|l|}{$\mathrm{EC} 50^{\mathrm{a}}$} & \multicolumn{2}{|c|}{$50 \%$ effect of $E 2^{b}$} \\
\hline & ZEN/ $\alpha-Z E L$ & $\mathrm{AOH}$ & ZEN/ $\alpha-Z E L$ & $\mathrm{AOH}$ \\
\hline$\alpha-\mathrm{ZEL}+\mathrm{AOH} 1: 250$ & $50 \mathrm{pM}$ & $12.5 \mathrm{nM}$ & $55 \mathrm{pM}$ & $13.75 \mathrm{nM}$ \\
\hline $\mathrm{ZEN}+\mathrm{AOH} 1: 250$ & $1.241 \mathrm{nM}$ & $310.25 \mathrm{nM}$ & $865 \mathrm{pM}$ & $216.25 \mathrm{nM}$ \\
\hline
\end{tabular}

${ }^{\text {a }}$ Concentration that gives $50 \%$ of the maximum effect level of each single substance

${ }^{\mathrm{b}}$ Concentration that gives $50 \%$ of the effect of $1 \mathrm{nME} 2$ of E2. As discussed below, this gives evidence for synergism. To verify whether the very high effects of combinations which reach the effect level of $1 \mathrm{nM}$ E2 depend on ER signaling, the highly potent combinations (10 nM ZEN or $\alpha$-ZEL $+2.5 \mu \mathrm{M} \mathrm{AOH)} \mathrm{were} \mathrm{co-incubated} \mathrm{with} \mathrm{the}$ high-affinity ER inhibitor ICI 182,780 . This co-incubation leads to complete inhibition of the effects detected for the combinations, which demonstrates their ER dependence (Fig. 4b) .

Results on measurements of constant ratio combinations between ZEN or $\alpha$-ZEL and AOH (1:250) are shown in Fig. 4. Sigmoidal dose-response curve fitting was performed for the combinations. According EC50 values and concentrations giving $50 \%$ of the effect of E2 are listed in Table 2. Evaluation of $\mathrm{CI}$ values over the whole effect range is presented in the effect-CI plots in Fig. $4 c$, $d$ and indicates mainly synergistic effects between ZEN or $\alpha$-ZEL and $\mathrm{AOH}$. Only at very low concentrations $(10 \mathrm{pM}+2.5 \mathrm{nM})$, combinations of $\alpha$-ZEL and $\mathrm{AOH}$ were found to mediate antagonism. Similar effects were extrapolated for combinations in very low concentrations of $\mathrm{ZEN}$ and $\mathrm{AOH}$ based on the effect-CI curve.

\section{Impact on cell growth and cytotoxicity}

In order to supplement the data on alkaline phosphatase stimuli, mycotoxins and binary combinations were tested in the SRB assay to assess potential growth stimulatory or cytotoxic effects. All experimental conditions were kept equal to the AlP activity measurements to enable direct comparison of the data sets. Effects of single substances in the SRB assay are illustrated in Fig. 1d. ZEN and $\alpha$-ZEL showed cell proliferating effects increasing with concentration up to $10 \mu \mathrm{M}$, whereas ZEN was found to be more potent than its metabolite. ZEN even mediated greater growth stimulation than E2 with a significant increase of 1.22 fold of total cell protein compared to the solvent control. $\alpha$-ZEL induced significant proliferation at $100 \mathrm{nM}$ reaching 1.13 fold of total cell protein, compared to the control. No cytotoxic effects were observed for both Fusarium metabolites at the tested concentrations. $\mathrm{AOH}$ did not induce proliferation, but was found to be cytotoxic at the highest concentrations of 5 and $10 \mu \mathrm{M}$. Due to these contrary effects on cellular proliferation on the one hand, and cytotoxicity on the other hand, it was not reasonable to generate curve fits and, more importantly, not possible to calculate combinatory effects by the combination index theorem (Chou 2006).

Figure $5 \mathrm{a}, \mathrm{b}$ illustrates heatmaps of all tested combinations and respective data on relative cell protein related to the solvent control. In accordance with measurements of single compounds, combinations of moderate to high concentrations of ZEN ( $100 \mathrm{nM}$ to $1 \mu \mathrm{M}$ ) and low concentrations of $\mathrm{AOH}$ (up to $1 \mu \mathrm{M}$ ) showed proliferative effects, whereas such effects could hardly be found in combinations with $\alpha$-ZEL. Nevertheless, in both data sets for combinations at high concentrations of $\mathrm{AOH}(5$ and $10 \mu \mathrm{M})$ predominantly cytotoxic effects were detected. In order to visualize the impact of $\mathrm{AOH}$ on the proliferative effects of ZEN and $\alpha$-ZEL, four exemplary graphs were drawn out of the data set. For each Fusarium compound, two line graphs are plotted showing effects of combinations with $\mathrm{AOH}$ in low and high concentrations, respectively, as well as the effects of the single substances (Fig. 5i-iv).

\section{Discussion}

\section{Evaluation of estrogenic effects}

Measurements of single mycotoxins confirmed previous reports that $\alpha$-ZEL is the most potent estrogen of the tested mycoestrogens followed by the parent compound ZEN and that AOH possesses comparably low estrogenic potency (Frizzell et al. 2011; Hagler et al. 1979; Lehmann et al. 2006; Metzler et al. 2010). Comparison of EC50 values in the AlP assay revealed a clear ranking according to estrogenicity as follows: $\alpha$-ZEL $>$ E2 $>$ ZEN $>$ AOH. However, these EC50 values depend on the maximum effect which can be achieved. This was found to be a substance specific property and explains why $\alpha$-ZEL exerts a lower EC50 value than E2 but may, however, not be considered as a stronger estrogen. Visual interpretation of the data shown in Fig. 1b clearly results in a more reasonable ranking of the substances according to estrogenicity which is also reflected by the corresponding concentrations of substances giving $50 \%$ of the effect of E2 shown in Table 1: E2 $>\alpha$-ZEL $>$ ZEN $>$ AOH. Not only the concentrations at 


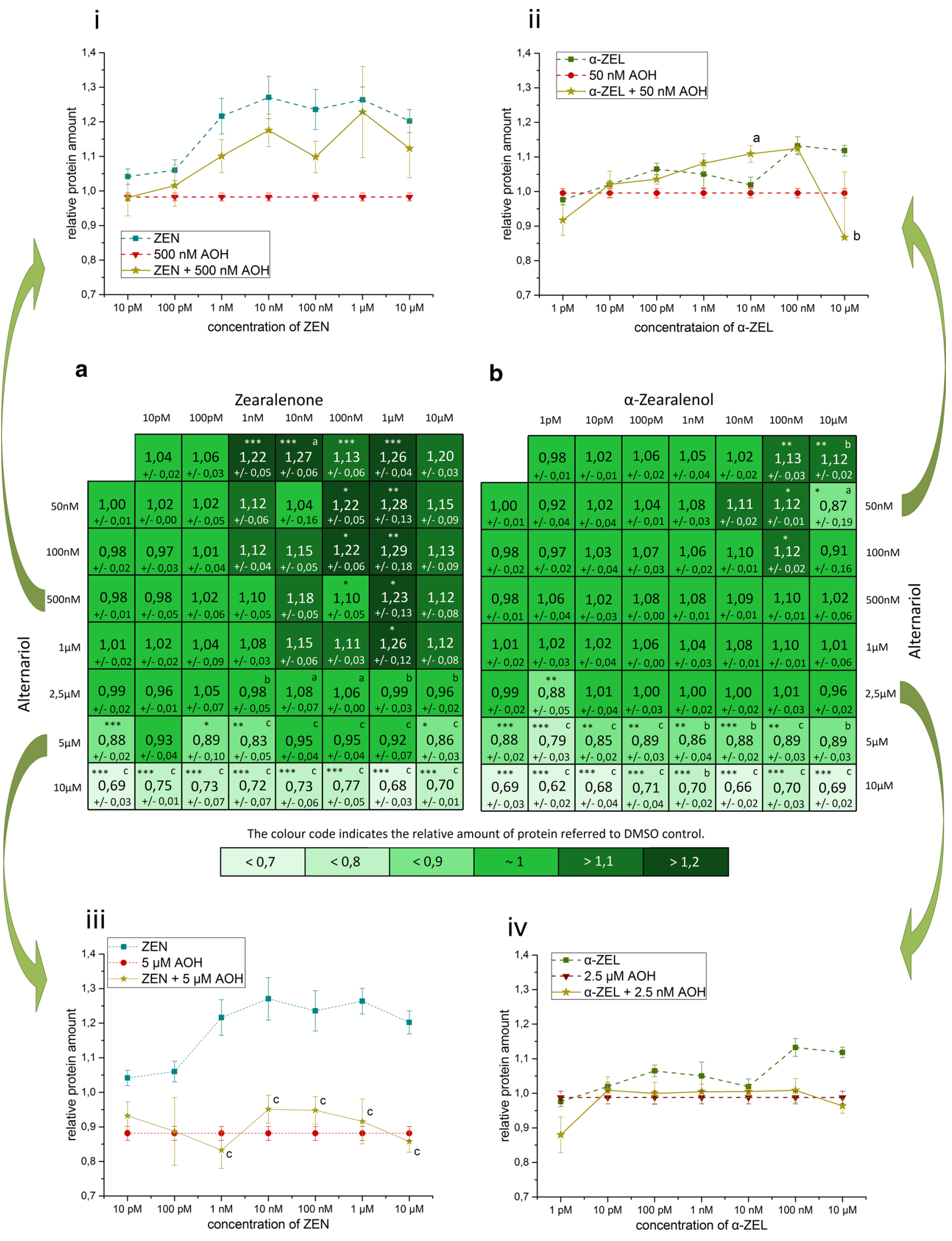


4Fig. 5 Heatmaps showing relative effects on cellular protein amount measured by the SRB assay, of single mycotoxins and binary combinations of AOH with (a) ZEN or (b) $\alpha$-ZEL (mean, SEM). Protein amount of the solvent control was set to 1 . Four line graphs covering whole concentration ranges of ZEN or $\alpha$-ZEL in combination with one low (i, ii) and one high (iii, iv) concentration of $\mathrm{AOH}$ are extracted exemplary from the data set for comparison with the effects of single substances. Significant differences of effects to the solvent control are indicated by asterisks, significant differences of the binary mixtures to measurements with ZEN or $\alpha$-ZEL, as single compounds, are indicated by a, b or c $\left(*,{ }^{\#} p>0.05 ; * *,{ }^{\# \#} p>0.01\right.$; ***, $\#$ \#\# $p$ 0.001). All measurements were repeated in at least three independent biological replicates, each measured in technical triplicates

which the substances induced effects but also the maximum potency of AlP activation differed among the compounds (Fig. 1b). All tested concentrations of $\alpha$-ZEL, ZEN or AOH showed significantly lower effects than E2. These findings suggest that $\alpha$-ZEL, ZEN and AOH act as partial agonists in this estrogenic system.

Interestingly, measurements of total cell protein levels in the SRB assay did not reflect these findings with respect to cell proliferation. Dose-response evaluation in the SRB assay of ZEN, as single substance, revealed higher proliferative effects than those caused by $\alpha$-ZEL or even by E2. This was not found in a classical E-screen study using MCF7 breast cancer cells (Molina-Molina et al. 2014). However, considering that an incubation time of $144 \mathrm{~h}$ was applied by Molina-Molina et. al., the strong proliferative effect of ZEN, found in our study, may depend on differences in the duration of exposure as well as cell line-specific responses.

In the present study, the maximum induction of AlP measured was not generated by the natural estrogen hormone E2. Several combinations of AOH with ZEN or $\alpha$-ZEL induced higher levels of AlP activity than E2, although not statistically significant from the E2 effect $(p<0.05)$. The highest effect was found for the combination of $10 \mathrm{nM}$ ZEN and $5 \mu \mathrm{M} \mathrm{AOH}$. Co-incubation of highly potent combinations with the ER inhibitor ICI 182,780 indicated that these strong effects also depend on ER signaling. In line with the potency of the single compounds, combinations of AOH and $\alpha$-ZEL showed increased AlP activity at much lower concentrations compared to combinations with ZEN. Combinations of $\alpha$-ZEL and $\mathrm{AOH}$ in concentrations below $1 \mathrm{nM}$ and $10 \mu \mathrm{M}$, respectively, resulted throughout in synergistic effects.

A general principle describes combinatory effects of substances that do not interact as simply additive. Accordingly, interactions between compounds are indicated, when the combinatory effect is not additive. The combination index theorem is the mathematical model of first choice, which allows quantitative assessment of synergistic or antagonistic effects (Chou 2006). To apply this model, effects of single substances and combinations need to be described by values between zero and one, standing for $0-100 \%$ estrogenic stimulus. However, since $\alpha$-ZEL, ZEN and $\mathrm{AOH}$ act as partial antagonists, $100 \%$ of activation needed to be set to a common value. Therefore, the value of 3.4, which lies slightly above the highest measurements obtained during this study, was defined as $100 \%$ AlP induction for calculation of the combinatory index (CI). Since only relative values are applied here, this approach is not expected to have a major impact on the calculation of combinatory indices and even minor effects on final conclusions, to be drawn from these. However, high concentrations of $\alpha$-ZEL and ZEN, above 1 and $10 \mathrm{nM}$, respectively, were not included in the calculations, as these would falsify the CI calculations of the whole data set, due to the partial antagonistic characteristics of the substances. Therefore, CI calculation was limited to combinations with ZEN below $100 \mathrm{nM}$ and $\alpha$-ZEL below $10 \mathrm{nM}$. However, considering the fact that the single substances act as partial agonist and therefore do not reach the potency of E2, but several combinations do, this may be considered as synergism per se. This was demonstrated by statistical analysis, which revealed significant differences of effects, of all single mycotoxin concentrations to the effect of E2 (thus significantly lower than the AIP level reached by E2) that is no longer true for several combinations. Summing up these results, interactions between $\mathrm{AOH}$ and ZEN or $\alpha$-ZEL were found to be synergistic over wide concentration ranges. A reasonable explanation for this synergism could be the fact that $\mathrm{AOH}$ has been reported to predominantly bind ER- $\beta$, whereas ZEN shows higher affinity to ER- $\alpha$ (Kuiper et al. 1998; Lehmann et al. 2006). This mechanism seems plausible since Ishikawa cells are known to express both estrogen receptor subtypes (Johnson et al. 2007) and are thus wellsuited for the performed experiments.

Combinations with the two highest concentrations of $\mathrm{AOH}(2.5$ and $5 \mu \mathrm{M})$ generally showed a decline of estrogenic effects compared to lower doses although still producing a significantly enhanced level of AlP activity. Here, cytotoxic effects of the mycotoxins presumably overlapped with estrogenic effects, as it was shown by the SRB measurements. The data of the SRB assay, in general, indicated that $\mathrm{AOH}$ reduces the proliferative effects of ZEN and $\alpha$-ZEL in a dose dependent manner. In fact, at these high concentrations of $\mathrm{AOH}$, of 2.5 and $5 \mu \mathrm{M}$, combinations showed slightly cytotoxic effects, which, however, are more pronounced in the presence of $\alpha$-ZEL than of ZEN. This reflects the results of cell protein measurements with the single substances, which showed that ZEN possesses a stronger proliferative potential than $\alpha$-ZEL under these experimental conditions and, therefore, may counteract the cytotoxicity of AOH more effectively. Interestingly, the reduction of protein amount is not explicitly reflected by a dramatic decrease of induction of AlP activity. The fact that 
the estrogenic effects on AlP are in general much more pronounced than the proliferative effects may give a reasonable explanation for this. An experimental setting with $48 \mathrm{~h}$ of incubation duration may simply be too short to observe stronger effects in proliferation in a cell line with a doubling time of 27-36 h (Nishida 2002).

Measurements on constant ratio combinations between ZEN or $\alpha$-ZEL and AOH also revealed, according to the CI evaluation, mainly synergistic effects. However, evaluated concentrations of the combinations giving $50 \%$ of the effect of E2 did not reveal a shift of the dose-response curve $\alpha$-ZEL when combined with AOH. A slight shift to the left could be detected for the curve of ZEN. ZEN alone reaches $50 \%$ effect of $\mathrm{E} 2$ at $1.423 \mathrm{nM}$, whereas in combination with $\mathrm{AOH}(1: 250)$ this effect is reached at $865 \mathrm{pM}$ $(+216 \mathrm{nM} \mathrm{AOH})$. Evaluation of combinatory effects resulted in quite extreme CI values (Fig. 4c, d), especially in low effect ranges considering that the data from the dose-response curves are reflected (Fig. 4a). It may be considered, however, that due to the 1:250 ratio several of the combined $\mathrm{AOH}$ concentrations are far below the effect range of $\mathrm{AOH}$ (below $50 \mathrm{nM}$ ). Accordingly, only slight changes in the low effect ranges might result in calculations of very strong combinatory effects. Anyhow, for both combinations, the evaluated dose-response curves again reveal similar effects to what was found previously. The maximum effects of the combinations exceed those of ZEN and $\alpha$-ZEL and reach the effect level of E2. As these effects were found to depend on ER signaling, they may be considered as estrogenic synergistic effects per se.

\section{Potential relevance for risk assessment on mixtures of mycoestrogens}

This study revealed synergistic estrogenic effects of the mycotoxin AOH in combination with ZEN or its phase I metabolite $\alpha$-ZEL. Whether these combinations may bear endocrine disruptive potential, as it is already known for ZEN, still needs to be answered by detailed elucidation of potential adverse effects in vivo. However, since mycotoxins are natural food contaminants, co-exposure of the human population seems to be most likely in many settings. As a consequence, priority shall be attributed to combinations of mycoestrogens and estrogenic food constituents in general. Recently, considerations on combinatory effects initiated a paradigm shift in risk assessment of all kinds of chemical substances that stipulates mixture effects to be included in future (EFSA 2013). This applies to substances with all possible modes of action; however, it seems to be of special importance for endocrine disruptors. Due to the high sensitivity of endocrine systems in general, potential effects of compounds might be pronounced even at very low concentrations. There are some studies investigating the combinatory effects of prominent anthropogenic endocrine disruptors like bisphenol-A, phthalates, polychlorinated biphenyls (PCBs) and dioxins, which indicate that endocrine effects of mixtures possibly occur below NOELs (Couleau et al. 2015; Crofton et al. 2005; Li et al. 2012b). Considering co-contamination of food products by several substances, human exposure to mixtures seems to be even more likely. Our data suggest that also mycoestrogen mixtures may lead to adverse effects even at very low concentrations due to synergistic interactions. As a consequence, current limit values like the tolerable daily intake (TDI) for humans or maximum tolerated levels for mycotoxins in food may need reconsideration, as they are at present still derived from risk evaluation of single substances (EFSA 2011). Our study highlights the importance of combinatory effects to be incorporated in future approaches of risk assessment.

Acknowledgments Dedicated to the occasion of the 60th birthday of Univ. Prof. Dr. Bernhard Keppler, Faculty of Chemistry, University of Vienna. Open access funding provided by University of Vienna. The authors would like to express their gratitude toward Verena Schmidt for additional measurements of E2. This study was funded by the University of Vienna.

Author contributions K.V. and D.M. designed research; K.V., K.H. and D.B. performed experiments; K.V., K.H, D.B., B.W. and D.M. analyzed and interpreted data; K.V., B.W. and D.M. wrote the manuscript.

\section{Compliance with ethical standards}

Conflict of interest The authors declare to have no conflict of interest.

Open Access This article is distributed under the terms of the Creative Commons Attribution 4.0 International License (http://creativecommons.org/licenses/by/4.0/), which permits unrestricted use, distribution, and reproduction in any medium, provided you give appropriate credit to the original author(s) and the source, provide a link to the Creative Commons license, and indicate if changes were made.

\section{References}

Abid-Essefi S, Ouanes Z, Hassen W, Baudrimont I, Creppy E, Bacha $\mathrm{H}$ (2004) Cytotoxicity, inhibition of DNA and protein syntheses and oxidative damage in cultured cells exposed to zearalenone. Toxicol In Vitro 18(4):467-474. doi:10.1016/j.tiv.2003.12.011

Abid-Essefi S, Bouaziz C, Golli-Bennour EE, Ouanes Z, Bacha H (2009) Comparative study of toxic effects of zearalenone and its two major metabolites alpha-zearalenol and beta-zearalenol on cultured human Caco-2 cells. J Biochem Mol Toxicol 23(4):233243. doi: $10.1002 /$ jbt. 20284

Bandera EV, Chandran U, Buckley B et al (2011) Urinary mycoestrogens, body size and breast development in new jersey girls. Sci Total Environ 409(24):5221-5227. doi:10.1016/j. scitotenv.2011.09.029

Belhassen H, Jiménez-Díaz I, Arrebola JP et al (2015) Zearalenone and its metabolites in urine and breast cancer risk: a case-control 
study in Tunisia. Chemosphere 128:1-6. doi:10.1016/j. chemosphere.2014.12.055

Bennett JW, Klich M (2003) Mycotoxins. Clin Microbiol Rev 16(3):497-516

Chou TC (1975) General procedure for determination of medianeffect doses by a double logarithmic transformation of doseresponse relationships. Fed Proc 34(3):228

Chou TC (2006) Theoretical basis, experimental design, and computerized simulation of synergism and antagonism in drug combination studies. Pharmacol Rev 58(3):621-681. doi:10.1124/ pr.58.3.10

Chou TC, Talalay P (1984) Quantitative analysis of dose-effect relationships: the combined effects of multiple drugs or enzyme inhibitors. Adv Enzyme Regul 22:27-55

Coe JE, Ishak KG, Ward JM, Ross MJ (1992) Tamoxifen prevents induction of hepatic neoplasia by zeranol, an estrogenic food contaminant. Proc Natl Acad Sci USA 89(3):1085-1089

Couleau N, Falla J, Beillerot A et al (2015) Effects of endocrine disruptor compounds, alone or in combination, on human macrophage-like THP-1 cell response. PLoS One 10(7):e0131428. doi:10.1371/journal.pone.0131428

Crofton KM, Craft ES, Hedge JM et al (2005) Thyroid-hormonedisrupting chemicals: evidence for dose-dependent additivity or synergism. Environ Health Perspect 113(11):1549-1554. doi:10.1289/ehp. 8195

Domijan AM, Peraica M, Cvjetkovic B, Turcin S, Jurjevic Z, Ivic D (2005) Mould contamination and co-occurrence of mycotoxins in maize grain in Croatia. Acta Pharm 55(4):349-356

EFSA (2011) Scientific opinion on the risks for public health related to the presence of zearalenone in food. EFSA J. doi:10.2903/j. efsa.2011.2197

EFSA (2013) International frameworks dealing with human risk assessment of combined exposure to multiple chemicals. EFSA J. doi:10.2903/j.efsa.2013.3313

Ezekiel CN, Sulyok M, Warth B, Krska R (2012) Multi-microbial metabolites in fonio millet (acha) and sesame seeds in Plateau State, Nigeria. Eur Food Res Technol 235:285-293. doi:10.1007/ s00217-012-1755-2

Fehr M, Pahlke G, Fritz J et al (2009) Alternariol acts as a topoisomerase poison, preferentially affecting the IIalpha isoform. Mol Nutr Food Res 53(4):441-451. doi:10.1002/mnfr.200700379

Frizzell C, Ndossi D, Verhaegen S et al (2011) Endocrine disrupting effects of zearalenone, alpha- and beta-zearalenol at the level of nuclear receptor binding and steroidogenesis. Toxicol Lett 206(2):210-217. doi:10.1016/j.toxlet.2011.07.015

Frizzell C, Ndossi D, Kalayou S et al (2013) An in vitro investigation of endocrine disrupting effects of the mycotoxin alternariol. Toxicol Appl Pharmacol 271(1):64-71. doi:10.1016/j. taap.2013.05.002

Frizzell C, Uhlig S, Miles CO et al (2015) Biotransformation of zearalenone and zearalenols to their major glucuronide metabolites reduces estrogenic activity. Toxicol In Vitro 29(3):575-581. doi:10.1016/j.tiv.2015.01.006

Gao F, L-p Jiang, Chen M et al (2013) Genotoxic effects induced by zearalenone in a human embryonic kidney cell line. Mut Res Genet Toxicol Environ Mutagen 755(1):6-10. doi:10.1016/j. mrgentox.2013.04.009

Gross-Steinmeyer K, Eaton DL (2012) Dietary modulation of the biotransformation and genotoxicity of aflatoxin B1. Toxicology 299(2-3):69-79. doi:10.1016/j.tox.2012.05.016

Hagler WM, Mirocha CJ, Pathre SV, Behrens JC (1979) Identification of the naturally occurring isomer of zearalenol produced by Fusarium roseum 'Gibbosum' in rice culture. Appl Environ Microbiol 37(5):849-853

Hickert S, Bergmann M, Ersen S, Cramer B, Humpf HU (2016) Survey of Alternaria toxin contamination in food from the German market, using a rapid HPLC-MS/MS approach. Mycotoxin Res 32(1):7-18. doi:10.1007/s12550-015-0233-7

Holinka CF, Hata H, Kuramoto H, Gurpide E (1986) Responses to estradiol in a human endometrial adenocarcinoma cell line (Ishikawa). J Steroid Biochem 24(1):85-89

Johnson SM, Maleki-Dizaji M, Styles JA, White IN (2007) Ishikawa cells exhibit differential gene expression profiles in response to oestradiol or 4-hydroxytamoxifen. Endocr Relat Cancer 14(2):337-350. doi:10.1677/ERC-06-0085

Kamyar M, Rawnduzi P, Studenik CR, Kouri K, Lemmens-Gruber $R$ (2004) Investigation of the electrophysiological properties of enniatins. Arch Biochem Biophys 429(2):215-223. doi:10.1016/j.abb.2004.06.013

Kuiper GJM, Lemmen JG, Carlsson B et al (1998) Interaction of estrogenic chemicals and phytoestrogens with estrogen receptor $\beta$. Endocrinology 139(10):4252-4263. doi:10.1210/ endo.139.10.6216

Lehmann L, Wagner J, Metzler M (2006) Estrogenic and clastogenic potential of the mycotoxin alternariol in cultured mammalian cells. Food Chem Toxicol 44(3):398-408. doi:10.1016/j. fct.2005.08.013

Li Y, Burns KA, Arao Y, Luh CJ, Korach KS (2012a) Differential estrogenic actions of endocrine-disrupting chemicals bisphenol $\mathrm{A}$, bisphenol $\mathrm{AF}$, and zearalenone through estrogen receptor alpha and beta in vitro. Environ Health Perspect 120(7):10291035. doi:10.1289/ehp.1104689

Li Z, Zhang H, Gibson M, Li J (2012b) An evaluation on combination effects of phenolic endocrine disruptors by estrogen receptor binding assay. Toxicol In Vitro 26(6):769-774. doi:10.1016/j. tiv.2012.05.017

Massart F, Meucci V, Saggese G, Soldani G (2008) High growth rate of girls with precocious puberty exposed to estrogenic mycotoxins. J Pediatr 152(5):690-5-695 e1. doi:10.1016/j. jpeds.2007.10.020

McErlean (1952) Vulvovaginitis of swine. Vet Rec 64:539-540

Metzler M, Pfeiffer E, Hildebrand A (2010) Zearalenone and its metabolites as endocrine disrupting chemicals. World Mycotoxin J 3(4):385-401. doi:10.3920/WMJ2010.1244

Molina-Molina J-M, Real M, Jimenez-Diaz I et al (2014) Assessment of estrogenic and anti-androgenic activities of the mycotoxin zearalenone and its metabolites using in vitro receptor-specific bioassays. Food Chem Toxicol 74:233-239. doi:10.1016/j.fct.2014.10.008

Nishida M (2002) The Ishikawa cells from birth to the present. Hum Cell 15(3):104-117

Pestka JJ (2010) Deoxynivalenol: mechanisms of action, human exposure, and toxicological relevance. Arch Toxicol 84(9):663-679. doi:10.1007/s00204-010-0579-8

Serrano AB, Font G, Manes J, Ferrer E (2013) Emerging Fusarium mycotoxins in organic and conventional pasta collected in Spain. Food Chem Toxicol 51:259-266. doi:10.1016/j.fct.2012.09.034

Shephard GS, Burger HM, Gambacorta L et al (2013) Mycological analysis and multimycotoxins in maize from rural subsistence farmers in the former Transkei, South Africa. J Agric Food Chem 61(34):8232-8240. doi:10.1021/jf4021762

Skehan P, Storeng R, Scudiero D et al (1990) New colorimetric cytotoxicity assay for anticancer-drug screening. J Natl Cancer Inst 82(13):1107-1112

Stob M, Baldwin RS, Tuite J, Andrews FN, Gillette KG (1962) Isolation of an anabolic, uterotrophic compound from corn infected with Gibberella zeae. Nature 196:1318

Streit E, Schwab C, Sulyok M, Naehrer K, Krska R, Schatzmayr G (2013) Multi-mycotoxin screening reveals the occurrence of 139 different secondary metabolites in feed and feed ingredients. Toxins (Basel) 5(3):504-523. doi:10.3390/toxins5030504

Sulyok M, Krska R, Schuhmacher R (2010) Application of an LC-MS/ MS based multi-mycotoxin method for the semi-quantitative 
determination of mycotoxins occurring in different types of food infected by moulds. Food Chem 119(1):408-416

Tiessen C, Fehr M, Schwarz C et al (2013) Modulation of the cellular redox status by the Alternaria toxins alternariol and alternariol monomethyl ether. Toxicol Lett 216(1):23-30. doi:10.1016/j. toxlet.2012.11.005

Uhlig S, Eriksen GS, Hofgaard IS, Krska R, Beltran E, Sulyok M (2013) Faces of a changing climate: semi-quantitative multimycotoxin analysis of grain grown in exceptional climatic conditions in Norway. Toxins (Basel) 5(10):1682-1697. doi:10.3390/ toxins 5101682

Vejdovszky K, Warth B, Sulyok M, Marko D (2016) Non-synergistic cytotoxic effects of Fusarium and Alternaria toxin combinations in Caco-2 cells. Toxicol Lett 241:1-8. doi:10.1016/j. toxlet.2015.10.024
Warth B, Parich A, Atehnkeng J et al (2012) Quantitation of mycotoxins in food and feed from Burkina Faso and Mozambique using a modern LC-MS/MS multitoxin method. J Agric Food Chem 60(36):9352-9363. doi:10.1021/jf302003n

Warth B, Sulyok M, Berthiller F, Schuhmacher R, Krska R (2013) New insights into the human metabolism of the Fusarium mycotoxins deoxynivalenol and zearalenone. Toxicol Lett 220(1):8894. doi:10.1016/j.toxlet.2013.04.012

Zhao K, Shao B, Yang D, Li F, Zhu J (2015) Natural occurrence of Alternaria toxins in wheat-based products and their dietary exposure in China. PLoS One 10(6):e0132019. doi:10.1371/journal. pone.0132019 